\title{
On Self-Scaling Variable-Metric Algorithms
}

\author{
Abbas Y.AL-Bayati \\ Mardin Sh. Taher \\ profabbasalbayati@yahoo.com \\ College of Computer sciences and Mathematics \\ University of Mosul/Iraq
}

Received on: 25/01/2005

Accepted on: 09/05/2005

ABSTRACT

In this paper, we have developed a new self-scaling VM-method for solving unconstrained nonlinear optimization problems. The numerical and theoretical results demonstrate the general effectiveness of the new self-scaling VM-method when compared with PHUA \& ZENG algorithm; we have tested these algorithms on several high-dimension test functions with promising numerical results.

Keywords: unconstrained optimization, nonlinear problems, self-scaling VMmethod.

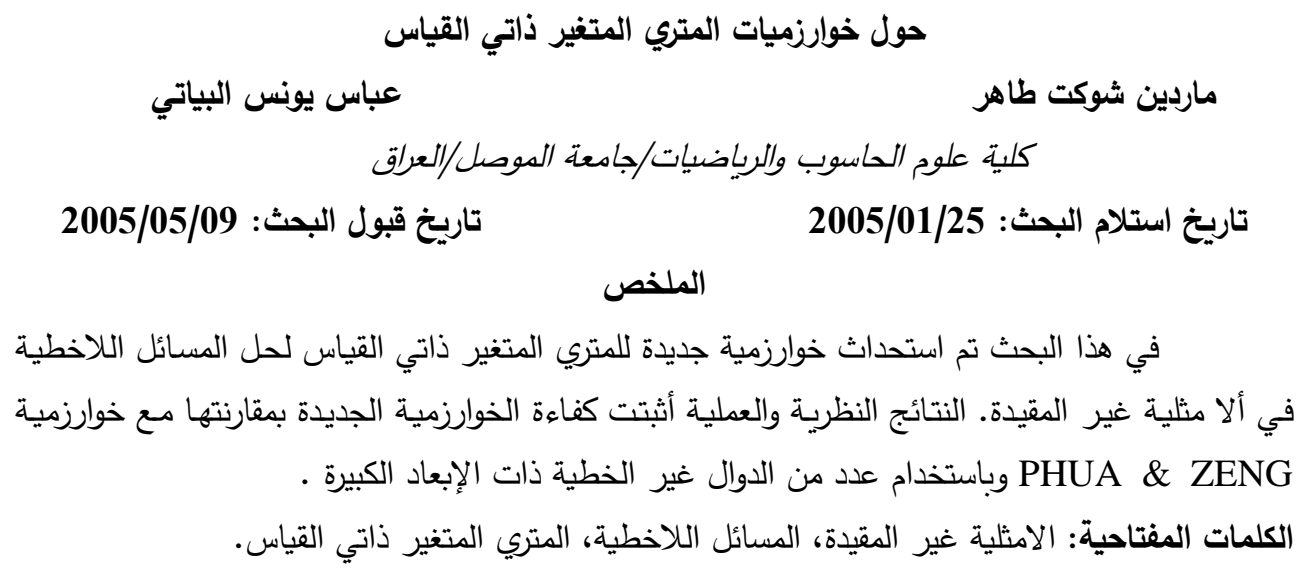

\section{1-Introduction}

In this section we begin with a numerical method for solving unconstrained nonlinear minimization problem

$$
\operatorname{minf}(x)
$$

where the function $f(x)$ is a twice continuously differentiable real valued function in $\mathrm{n}$-dimensional space.

A popular class of method for solving (1) is the Quasi-Newton (QN) or Variable Metric (VM) methods. Given an initial point $\mathrm{x}_{1}$, an nxn matrix $\mathrm{H}_{1},\left(\mathrm{H}_{1}\right.$ is non-singular $), \mathrm{VM}$-methods proceed to generate the following iterative sequence at the $\mathrm{k}^{\text {th }}$ iteration: -

1- Compute $g_{k}=\nabla f\left(x_{k}\right)$, the gradient of the function $f(x)$ at the current point $\mathrm{x}_{\mathrm{k}}$. 
2- Compute the search direction

$$
\mathbf{d}_{\mathrm{k}}=-\mathbf{H}_{\mathrm{k}} \mathbf{g}_{\mathrm{k}}
$$

3- Apply an appropriate line search strategy along the search direction $\mathrm{d}_{\mathrm{k}}$ to find a step-size $\alpha_{k}>0$, such that the following Wolf's condition are satisfied:

$$
\begin{aligned}
& f\left(x_{k}+\alpha_{k} d_{k}\right) \leq f\left(x_{k}\right)+\beta_{1} \alpha_{k} g^{T} d_{k} d_{k} \\
& g\left(x_{k}+\alpha_{k} d_{k}\right)^{T} d_{k} \geq \beta_{2} g^{T} d_{k}
\end{aligned}
$$

where $0<\beta_{1}<0.5$ and $\beta_{1}<\beta_{2}<1$.

4- Set $\quad \mathbf{x}_{\mathbf{k}+1}=\mathbf{x}_{\mathbf{k}}+\boldsymbol{\alpha}_{\mathbf{k}} \mathbf{d}_{\mathbf{k}}$.

5- Update the $\mathrm{H}_{\mathrm{k}}$ by

$$
\mathbf{H}_{\mathrm{k}+\mathbf{1}}=\mathbf{H}_{\mathrm{k}}+\Delta \mathbf{H}_{\mathrm{k}} \text {. }
$$

where $\Delta \mathrm{H}_{\mathrm{k}}$ is a correction matrix .Usually, $\mathrm{H}_{1}=\mathrm{I}$ is chosen , and the updating matrix $\mathrm{H}_{k+1}$ is chosen to satisfy the following QN- like condition

$$
\mathbf{H}_{\mathrm{k}+1} \mathbf{y}_{\mathbf{k}}=\lambda_{\mathrm{k}} \mathbf{v}_{\mathbf{k}}
$$

$$
\text { where } v_{k}=x_{k+1}-x_{k} \text {, }
$$

$$
\mathrm{y}_{\mathrm{k}}=\mathrm{g}_{\mathrm{k}+1^{-}} \mathrm{g}_{\mathrm{k}} \text {, and } \lambda_{\mathrm{k}} \text { is scalar }
$$

A general class of QN updates was proposed by Broyden (1967).

$H_{k+1}=H_{k}-\left(H_{k} y_{k} y^{T_{k}} H_{k}\right) /\left(y^{T_{k}} H_{k} y_{k}\right)+v_{k} v^{T_{k} / v^{T}}{ }_{k} y_{k}+\phi_{k}\left(y^{T}{ }_{k} H_{k} y_{k}\right) R_{k} R^{T} T_{k}$ where

$$
\begin{aligned}
& \mathbf{R}_{k}=\mathbf{v}_{k} / v_{k} \mathbf{T}_{k}-H_{k} y_{k} / \mathbf{y}^{T_{k}} H_{k} \mathbf{y}_{k}
\end{aligned}
$$

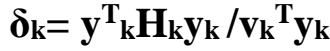

$$
\begin{aligned}
& \boldsymbol{\mu}_{\mathrm{k}}=\mathbf{v}^{\mathrm{T}} \mathbf{k}_{\mathbf{k}} \mathbf{H}_{\mathbf{k}} / \mathbf{v}_{\mathbf{k}} \mathbf{T}_{\mathbf{k}} \\
& \phi_{\mathrm{k}}=\phi_{\mathrm{k}}\left(\theta_{\mathrm{k}}\right)=\left(1-\theta_{\mathrm{k}}\right) /\left(1+\theta_{\mathrm{k}}\left(\delta_{\mathrm{k}} \mu_{\mathrm{k}}\right)\right)
\end{aligned}
$$

where $\theta_{\mathrm{k}} \in \mathrm{R}$ is parameter;

The most popular QN-methods are defined from (8) by choosing different values of $\theta_{\mathrm{k}}$,

For $\theta_{\mathrm{k}}=\mathrm{v}^{\mathrm{T}} \mathrm{kyk}_{\mathrm{k}} /\left(\mathrm{v}^{\mathrm{T}} \mathrm{k}_{\mathrm{k}}-\mathrm{v}^{\mathrm{T}}{ }_{\mathrm{k}} \mathrm{H}_{\mathrm{k}} \mathrm{v}_{\mathrm{k}}\right)$, we get the symmetric rank-one formula, Broyden (1967).

For $\theta_{\mathrm{k}}=1$, we get the DFP formula, due to Davidon, Fletcher and Powll(1963).

For $\theta_{\mathrm{k}}=0$, we get the BFGS formula , due to Broyden, Fletcher,Goldfarb and Shanno (1970).

\section{2-The modification of QN-methods}

These methods can be expressed as follows: -

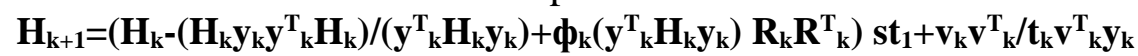
such that chosen $\mathrm{H}_{\mathrm{k}+1}$ to satisfy the following modified QN- Condition

$$
\mathbf{H}_{\mathbf{k}+1} \mathbf{y}_{\mathbf{k}}=\boldsymbol{\lambda}_{\mathbf{k}} \mathbf{V}_{\mathbf{k}}
$$

where $\lambda_{\mathrm{k}}>0$ is scaling parameter ; 
$t_{k}=1 / \lambda_{k}=\left(6\left(f\left(x_{k}\right)-f\left(x_{k+1}\right)+v^{T} g_{k+1}\right) / v^{T} y_{k}\right)-2$

$\gamma_{k}=t_{k} g^{T}{ }_{k V k} / g^{T} H_{k} H_{k}+\left(1-t_{k}\right) v^{T}{ }_{k y k} / y^{T} \mathbf{T}_{k} H_{k} y_{k}$

and $\phi_{\mathrm{k}}$ is defined by (12)

now we have special families for (13), like

$1-\mathrm{H}_{\mathrm{k}+1}\left(\phi_{\mathrm{k}}, 1,1\right)=$ the Broyden family of QN-update(1970).

2- $\mathrm{H}_{\mathrm{k}+1}\left(\phi_{\mathrm{k}}, 1, \mathrm{t}_{\mathrm{k}}\right)=$ the Biggs family of modified BFGS update(1973).

3- $\mathrm{H}_{\mathrm{k}+1}\left(\phi_{\mathrm{k}}, \mathrm{st}_{1}, 1\right)=$ the Oren family of self -scaling QN-update(1974).

$4-\mathrm{H}_{\mathrm{k}+1}\left(\phi_{\mathrm{k}}, 1, \sigma_{\mathrm{k}}\right)=$ AL-Bayati's(1991)self-scaling method with $\sigma_{\mathrm{k}}=\mathrm{y}^{\mathrm{T}}{ }_{\mathrm{k}} \mathrm{H}_{\mathrm{k}} \mathrm{y}_{\mathrm{k}}$ $/ \mathrm{v}_{\mathrm{k}}^{\mathrm{T}} \mathrm{y}_{\mathrm{k}}$

5- $\mathrm{H}_{\mathrm{k}+1}\left(\phi_{\mathrm{k}}, \mathrm{st}_{1}, \mathrm{t}_{\mathrm{k}}\right)=$ the PHUA\&ZENG family of self -scaling QN-update. where the parameter $\left(\mathrm{st}_{1}\right)$ can be chosen as:

$\mathrm{st}_{1}=\left(\begin{array}{ccc}\varepsilon_{1} & \text { if } & \gamma_{\mathrm{k}} \leq \varepsilon_{1} \\ \gamma_{\mathrm{k}} & \text { if } & \varepsilon_{1} \leq \gamma_{\mathrm{k}} \leq \varepsilon_{2} \\ \varepsilon_{2} & \text { if } & \gamma_{\mathrm{k}}>\varepsilon_{2}\end{array}\right)$

where $\varepsilon_{1}$ is a small positive constant, $\varepsilon_{2}$ is bigger constant and $\gamma_{\mathrm{k}}$ is defined by(16)

\section{3-New self-scaling VM-algorithm}

However, we can modify the above algorithm by using our new selfscaling QN-update which is given by

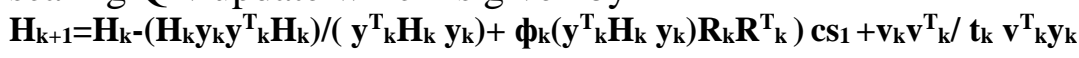
where the parameter $\left(\operatorname{cs}_{1}\right)$ can be chosen as:

$$
\mathrm{cs}_{1}=\left(\begin{array}{ccc}
\mathrm{st}_{1} & \text { if } & \mathrm{st}_{1} \geq \mathrm{st}_{2} \& \mathrm{st}_{2}>\mathrm{t}_{\mathrm{k}} \\
\mathrm{st}_{2} & \text { otherwise }
\end{array}\right)
$$

where $\quad \mathrm{st}_{2}=\mathrm{v}_{\mathrm{k}}^{\mathrm{T}} \mathrm{y}_{\mathrm{k}} / \mathrm{y}^{\mathrm{T}} \mathrm{k}_{\mathrm{k}} \mathrm{y}_{\mathrm{k}}$

where $\quad \mathrm{st}_{1}$ is defined by (17), $\mathrm{t}_{\mathrm{k}}$ is defined by(15) we can see that the new algorithm satisfies the quasi-Newton like condition $\mathrm{H}_{\mathrm{k}+1} \mathrm{y}_{\mathrm{k}}=\left(\mathrm{cs}_{1}\right) \mathrm{v}_{\mathrm{k}}$, and it generates conjugate search directions. 


\section{Theorem (3.1): -}

Assume that $f(x)$ be a quadratic function defined by $f(x)=1 / 2 x^{T} G x+b^{T} x$, where $G$ is symmetric positive definite matrix,$b$ is constant . If the new $\mathrm{H}_{\mathrm{k}+1}$ is any symmetric positive definite matrix then we can define a new updating formula (18) and (19), and the search direction $\mathrm{d}_{\mathrm{k}+1}{ }^{\text {new }}=-\mathrm{H}_{\mathrm{k}+1} \mathrm{~g}_{\mathrm{k}+1}$ is identical to the CG-direction defined by

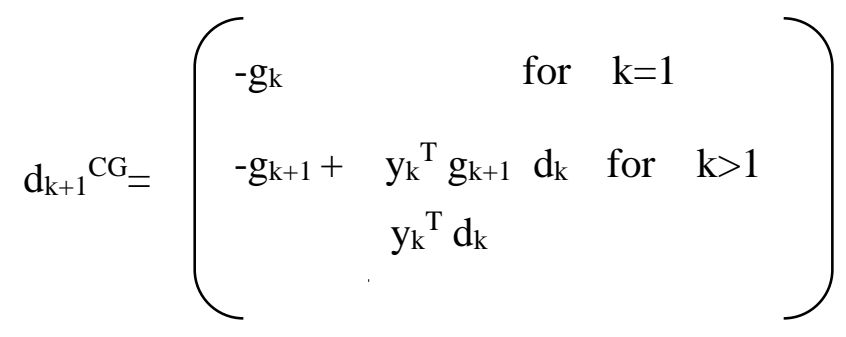

\section{proof:}

The updating formula (18)-(19) can be written as $\mathbf{H}_{k+1}{ }^{\text {new }}=\left(\mathbf{H}_{k}-\mathbf{v k y}^{\mathrm{T}}{ }_{\mathrm{k}} \mathbf{H}_{\mathrm{k}} / \mathbf{v}_{\mathrm{k}}{ }^{\mathrm{T}} \mathbf{y}_{\mathrm{k}}-\right.$ $\left.H_{k y k} V_{k}^{T} / v_{k}^{T} y_{k}\right) \operatorname{cs} 1+\left(1+y^{T}{ }_{k} H_{k} y_{k} / v_{k}{ }^{T} y_{k}\right) V_{k} V_{k}^{T} / t_{k} v^{T} y_{k}$ Now Let $\mathrm{d}_{\mathrm{k}+1}=-\mathrm{H}_{\mathrm{k}+1} \mathrm{~g}_{\mathrm{k}+1}$ $d_{k+1}=-H_{k} g_{k+1}\left(\operatorname{css}_{1}\right)+y^{T}{ }_{k} H_{k} g_{k+1}\left(\operatorname{css}_{1}\right) v_{k} / v_{k}{ }^{T} y_{k}+v_{k}{ }^{T} g_{k+1} H_{k} y_{k}\left(\operatorname{cs}_{1}\right) / v_{k}{ }^{T} y_{k}-\left(y^{T} H_{k}\right.$ $\left.\left.\mathbf{y}_{\mathbf{k}}\right) \mathbf{v}_{\mathbf{k}} \mathbf{T}_{\mathbf{k}+1} \mathbf{v}_{\mathbf{k}} / \mathbf{t}_{\mathbf{k}} \mathbf{v}_{\mathbf{k}}^{\mathrm{T}} \mathbf{y}_{\mathbf{k}}\right)-\mathbf{v}_{\mathbf{k}}{ }^{\mathrm{T}} \mathbf{g}_{\mathbf{k}+1} \mathbf{v}_{\mathbf{k}} / \mathbf{t}_{\mathbf{k}} \mathbf{v}^{\mathrm{T}} \mathbf{y}_{\mathbf{k}}$ since $\mathrm{v}_{\mathrm{k}}^{\mathrm{T}} \mathrm{g}_{\mathrm{k}+1}=0$ for exact line search, then $d_{k+1}=-(\operatorname{cs} 1) H_{k} g_{k+1}+y^{T}{ }_{k} H_{k} g_{k+1}\left(\operatorname{css}_{1}\right) d_{k} / v^{T} y_{k}$

for constant (cs1), it is clear that equation (21)is identical search direction for $\operatorname{cs} 1=1$, or a parallel search directions with a multiple of (cs1) i.e. $\mathrm{H}_{\mathrm{k}+1} \mathrm{y}_{\mathrm{k}}=\left(\mathrm{cs}_{1}\right) \mathrm{v}_{\mathrm{k}}$ hence the proof .\#

It is like standard CG-method in its global convergence property. For more details see (WANG and Li, 2005).

\section{4-Numerical results}

Our computation results involved a number of well-known nonlinear functions with different dimensions. The results are performed in double precision using programs written in Fortran.

All the algorithms use exactly the same line search strategy which is the cubic fitting technique, directly adapted from Bundy (1984), these algorithms are assumed to have convergence when each element of the 
gradient vector is less than $1 . \mathrm{E}-5$, that is $\|\mathrm{gk}+1\|<1$.E-5

Our numerical results are presented in two tables (1) and (2), the comparative performance of all the algorithm is evaluated by considering the total number of function evaluations (NOF) and the total number of iterations (NOI).

Table (1) contains the results for problems of dimensionality between 4 and 20 i.e. $(4 \leq n \leq 20)$ and table (2) contains the results for problems of dimensionality between 100 and 500 i.e. $(100 \leq n \leq 500)$.

In table (1) we can see that the new modified algorithm (new) improves PHUA \&ZENG algorithm about $45 \%$ NOI and $25 \%$ NOF, and in table (2) we can see that the new modified algorithm (new) improves PHUA\&ZENG algorithm about53\% NOI and 31\% NOF .As a general conclusion we can say that a proper self-scaling technique is very effective for large scale problems if it is well-defined theoretically, experimentally and for this group of selected functions .

Table (1.a)

Comparison between new and PHUA and ZENG method for $4 \leq \mathrm{n} \leq \mathbf{2 0}$

\begin{tabular}{|c|c|c|c|c|c|}
\hline \multirow{2}{*}{$\begin{array}{c}\text { Test } \\
\text { Function }\end{array}$} & \multirow{N}{*}{} & \multicolumn{2}{|c|}{ PHUA\&ZENG } & \multicolumn{2}{|c|}{ New } \\
\cline { 3 - 6 } & & NOI & NOF & NOI & NOF \\
\hline Cubic & 4 & 20 & 58 & 14 & 55 \\
Powll & 4 & 22 & 71 & 27 & 92 \\
Miele & 4 & 25 & 74 & 25 & 91 \\
Wood & 4 & 38 & 106 & 20 & 71 \\
Wolfe & 4 & 7 & 16 & 9 & 24 \\
Rosen & 4 & 33 & 92 & 17 & 72 \\
Sum & 4 & 4 & 24 & 5 & 28 \\
Non-Diagonal & 4 & 26 & 66 & 19 & 64 \\
Cubic & 20 & 34 & 87 & 14 & 55 \\
Powll & 20 & 37 & 98 & 37 & 123 \\
Miele & 20 & 35 & 98 & 26 & 93 \\
Wood & 20 & 89 & 227 & 20 & 71 \\
Wolfe & 20 & 24 & 50 & 26 & 75 \\
Rosen & 20 & 96 & 255 & 18 & 78 \\
Non-Diagonal & 20 & 52 & 117 & 21 & 86 \\
\hline \multicolumn{2}{|c|}{ Total } & 542 & 1439 & 298 & 1078 \\
\hline
\end{tabular}


Table (1.b)

Performance percentage of improving

\begin{tabular}{|c|c|c|}
\hline Tools & PHUA\&ZENG & New \\
\hline NOI & $100 \%$ & $55 \%$ \\
\hline NOF & $100 \%$ & $75 \%$ \\
\hline
\end{tabular}

Table (2.a)

Comparison between new and PHUA\&ZENG method for $\mathbf{1 0 0} \leq \mathrm{n} \leq \mathbf{5 0 0}$

\begin{tabular}{|c|c|c|c|c|c|}
\hline \multirow{2}{*}{$\begin{array}{c}\text { Test } \\
\text { function }\end{array}$} & \multirow{2}{*}{ N } & \multicolumn{2}{|c|}{ PHUA\&ZENG } & \multicolumn{2}{|c|}{ New } \\
\cline { 3 - 6 } & & NOI & NOF & NOI & NOF \\
\hline Cubic & 100 & 43 & 106 & 14 & 55 \\
Powll & 100 & 52 & 131 & 42 & 138 \\
Miele & 100 & 35 & 101 & 26 & 93 \\
Wood & 100 & 72 & 145 & 42 & 127 \\
Wolfe & 100 & 92 & 212 & 21 & 87 \\
Non-Diagonal & 500 & 48 & 115 & 14 & 55 \\
Powll & 500 & 47 & 116 & 42 & 131 \\
Miele & 500 & 39 & 106 & 27 & 96 \\
Wolfe & 500 & 82 & 165 & 45 & 136 \\
Non-Diagonal & 500 & 111 & 276 & 22 & 92 \\
\hline \multicolumn{7}{|c|}{ Total } & $\mathbf{6 2 1}$ & $\mathbf{1 4 7 3}$ & $\mathbf{2 9 5}$ & $\mathbf{1 0 1 2}$ \\
\hline
\end{tabular}

Table (2.b)

Performance percentage of improving

\begin{tabular}{|c|c|c|}
\hline Tools & PHUA\&ZENG & New \\
\hline NOI & $100 \%$ & $47 \%$ \\
\hline NOF & $100 \%$ & $69 \%$ \\
\hline
\end{tabular}

\section{5-Appendix}

All the test functions are from general literature.

1-Cubic function: -

$\mathrm{f}=100\left(\mathrm{x}_{2}-\mathrm{x}_{1}^{3}\right)^{2}+\left(1-\mathrm{x}_{1}\right)^{2}$

$$
\mathrm{x}_{0}=(-1.2,1)^{\mathrm{T}}
$$




\section{2-Generalized Powll function: -}

$\mathrm{n} / 4$

$\mathrm{f}=\sum\left[\left(\mathrm{x}_{4 \mathrm{i}-9}-10 \mathrm{x}_{4 \mathrm{i}-2}\right)^{2}+5\left(\mathrm{x}_{4 \mathrm{i}-1}-\mathrm{x}_{4 \mathrm{i}}\right)^{2}+\left(\mathrm{x}_{4 \mathrm{i}-2}-2 \mathrm{x}_{4 \mathrm{i}-1}\right)^{2}+10\left(\mathrm{x}_{4 \mathrm{i}-9}-10 \mathrm{x}_{4 \mathrm{i}}\right)^{2}\right]$, $\mathrm{i}=1$ $\mathrm{x}_{0}=(3,-1,0,1, \ldots)^{\mathrm{T}}$

3-Generalized Miele function: -

$\mathrm{n} / 4$

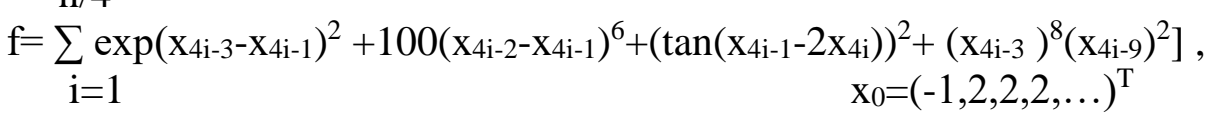

\section{4- Wolfe function: -}

$$
\begin{array}{r}
\left.\left.\left.\mathrm{f}=\left[-\mathrm{x}_{1}\left(3-\mathrm{x}_{1} / 2\right)+2 \mathrm{x}_{2}-1\right)\right]^{2}+\sum_{\mathrm{i}=1}^{\mathrm{n}}\left[\mathrm{x}_{\mathrm{i}-1}-\mathrm{x}_{1}\left(3-\mathrm{x}_{1} / 2\right)+2 \mathrm{x}_{2}-1\right)\right]^{2}+\left[-\mathrm{x}_{1}\left(3-\mathrm{x}_{1} / 2\right)+2 \mathrm{x}_{2}-1\right)\right]^{2}, \\
\mathrm{x}_{0}=(-1, \ldots)^{\mathrm{T}}
\end{array}
$$

5-Non-diagonal variant of Rosenbrock function: -
$\mathrm{n} / 2$
$\mathrm{f}=\sum_{\mathrm{i}=1}\left[100\left(\mathrm{x}_{1}-\mathrm{x}_{\mathrm{i}}^{2}\right)^{2}+\left(1-\mathrm{x}_{\mathrm{i}}\right)^{2}\right]$
$\mathrm{x}_{0}=(-1, \ldots)^{\mathrm{T}}$

6-Rosenbrock function: -
$\mathrm{n} / 2$
$\mathrm{f}=\sum\left[100\left(\mathrm{x}_{1}-\mathrm{x}_{\mathrm{i}}^{2}\right)^{2}+\left(1-\mathrm{x}_{\mathrm{i}}\right)^{2}\right]$
$\mathrm{X}_{0}=(-1.2,1, \ldots)^{\mathrm{T}}$
$\mathrm{i}=1$ 


\section{REFERENCES}

[1] Al-Bayati, A.Y. (1991) "A New Family Of Self- Scaling VariableMetric Algorithms for Unconstrained Optimization", Journal of education and Science, (12), PP.25-54.

[2] Bunday, B. (1984) Basic Optimization Methods, London, Edward Arnold.

[3] Broyden, C.G. (1970) "The Convergence of a Class of DoubleRank Minimization Algorithms", Journal of Institute of Mathematics , and its Application, (6), PP.221-231.

[4] Broyden, C.G. (1967) "Quasi-Newton Method and their Application to function Minimization ”,Math. Comp., 21, PP.368-381.

[5] Biggs, M.C. (1973) "A Note on Minimization Algorithm Which Make Use of Non-Quadratic Properties of the Objective Function ", Journal of Institute of Mathematics ,and its Application,(12), PP.337-338.

[6] Fletcher, R. and M.J.D. Powll (1963) "A Rapidly Convergent Descent Method For minimization", Computer Journal,(6),PP.163168.

[7] Goldfarb, D. (1970) " A Family of Variable Metric Updates Derived Variational Means "Mathematics of computations,(24), PP.23-26

[8] Oren, S.S. (1974) "On Selection of Parameters in Self Scaling Variable" mathematical programming, 3,1974.

[9] Shanno D.F. (1970) "Conditioning of Quasi-Newton Method for Unconstrained optimization", Mathematics of computations ,24, PP.647-656.

[10] WANG,C. and M. Li (2005) "Convergence Property of the FRCG with Error ", Journal of industrial and management optimization, Vol. (1),(2), PP.193-200. 